\title{
Eagle's Syndrome
}

Srinivas Gadipelly ${ }^{1}$, Srilatha Tunkimetla², Sheraz Bar Shaik ${ }^{3}$, Vijay Kumar Nellore4, Zainuddin Elyas khanny ${ }^{5}$

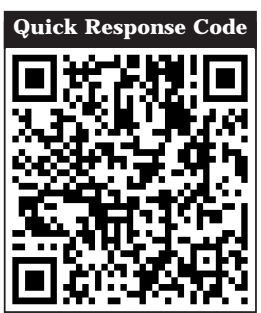

doi: $10.5866 / 2016.8 .10179$

1Professor Department of Oral and Maxillofacial Surgery, Kamineni Institute of Dental sciences, Narketpally, Nalgonda (Dt), Pin: 508254

2,3,4 \& 5Post graduate Department of Oral and Maxillofacial Surgery, MNR Dental College \& Hospital, Sangareddy, Medak (Dt)

\section{Article Info:}

Received: J uly 10, 2016

Review Completed: August 9, 2016

Accepted: September 8, 2016

Available Online: December, 2016 (www.nacd.in) (c) NAD, 2016 - All rights reserved

\section{E mail for correspondence:}

apollomaxfacs@gmail.com

\begin{abstract}
:
Eagle's syndrome (ES) occurs when an el ongated styloid process or calcified styl ohyoid ligament causes recurrent throat pain or foreign body sensation, dysphagia, or facial pain and which may radiate to the ipsilateral ear. The symptoms related to this condition can be confused with those attributed to a widevariety of facial neural gias. ES can be diagnosed radiologically and by physical examination. The treatment of ES is primarily surgical. The styloid process can be shortened through an intraoral or external approach. In this paper a case of ES exhibiting unilateral symptoms with bilateral el ongation of styloid process is reported.
\end{abstract}

Key words: Eagle's syndrome, Elongated styloid process, Stylohyoid ligament.

\section{INTRODUCTION}

Eagle's syndrome (ES) consists of craniofacial and neck pain due to el ongation of thestyloid process and/or calcification of the stylohyoid ligament. ${ }^{1}$ The normal length of the styloid process ranges from 2 to $3 \mathrm{~cm}$ and it is hardly palpable. ES mostly affects women and is usually an asymptomatic disease that is mostly seen in $3^{\text {rd }}$ to $5^{\text {th }}$ decades of life. According to Eagle, two types of the syndrome have been described: (1) the classic syndrome characterized by pain in the tonsillar fossa, sometimes associated with dysphagia and hypersalivation, and often followed by tonsillectomy and (2) the styloid-carotid syndrome: the styloid process compresses the car otid arteries and exerts particular pressure on its sympathetic fibers. We report the case of a young female patient with $\mathrm{ES}$.

\section{CASE REPORT}

A 26 year old female patient reported with complaint of pain in the left side of the throat since 6 months which radiates to ipsilateral ear, eye, and head. Pain is initiated and aggravated by eating food and swallowing. No pain was noticed on the right side. Except for tenderness while pressing externally behind the angle of mandible and intra-orally in the left tonsillar fossa, no other abnormality is detected. 
Small rudimentary tonsils were seen bilaterally. On general examination nothing was remarkable. CT scan of the base of the skull reports bilateral elongated styloid processes with no focal areas of non-ossification of stylohyoid ligament (Figure 1A). Styloid process on right side measured approximately $5.2 \mathrm{~cm}$ length while on the left side it is $5.7 \mathrm{~cm}$. Inferior most portion of the left stylohyoid ligament is not ossified and rest of the skull base bones appears normal. Haematological and biochemical tests were within the normal levels.

Patient was diagnosed as having throat pain due to elongated left styloid process. Patient underwent excision of the styloid process by intraoral approach, after removing the left tonsil and retraction of the superior constrictor muscle of the pharynx by blunt dissection to expose the el ongated styloid process. Approximately $2 \mathrm{cms}$ long styloid process resected out. Wound left open to heal by secondary intention. Patient reviewed after couple of months and when presented with no pain and healed wound.

\section{DISCUSSION}

E agle's syndrome is a rare condition of unknown pathophysiology and etiology. ${ }^{2}$ It can be idiopathic, congenital (due to persistence of cartilage el ements of the precursors of the styloid process) or acquired. Pietro Marchetti observed an elongation of the styloid process in the 17th century but in 1937 it
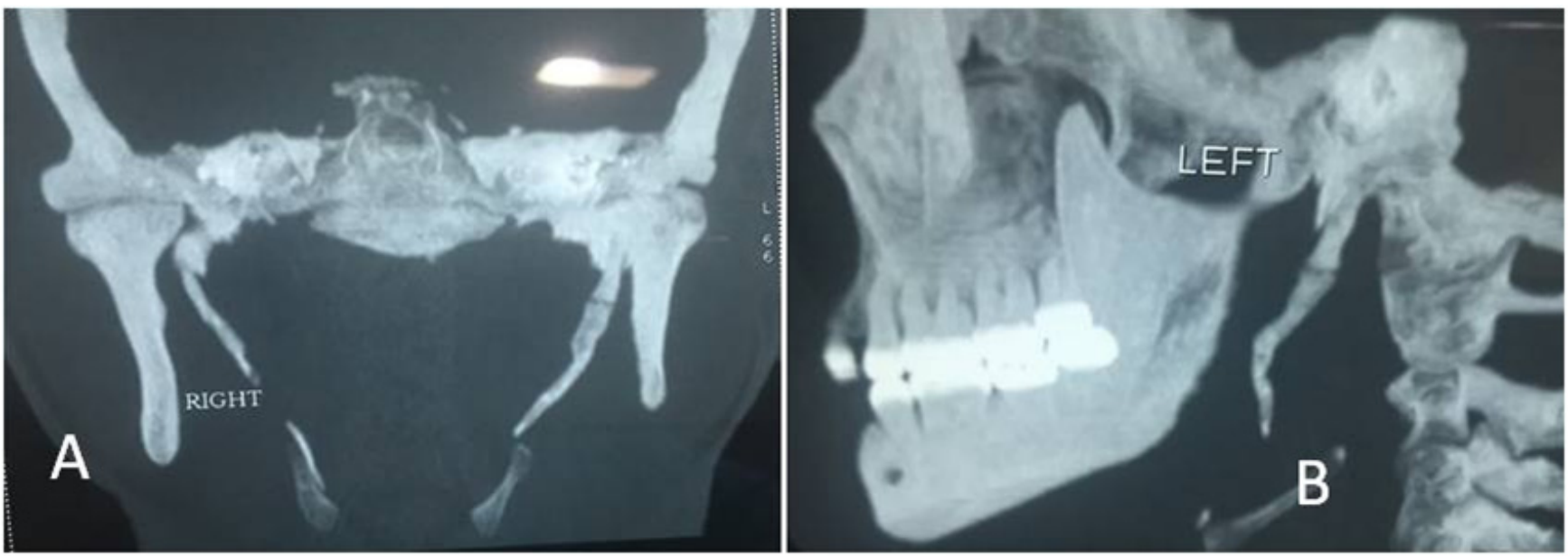

Figure 1: (A) CT base of the skull showing el ongated right and left styloid processes. (B): CT scan of the left styloid process (Type: II).

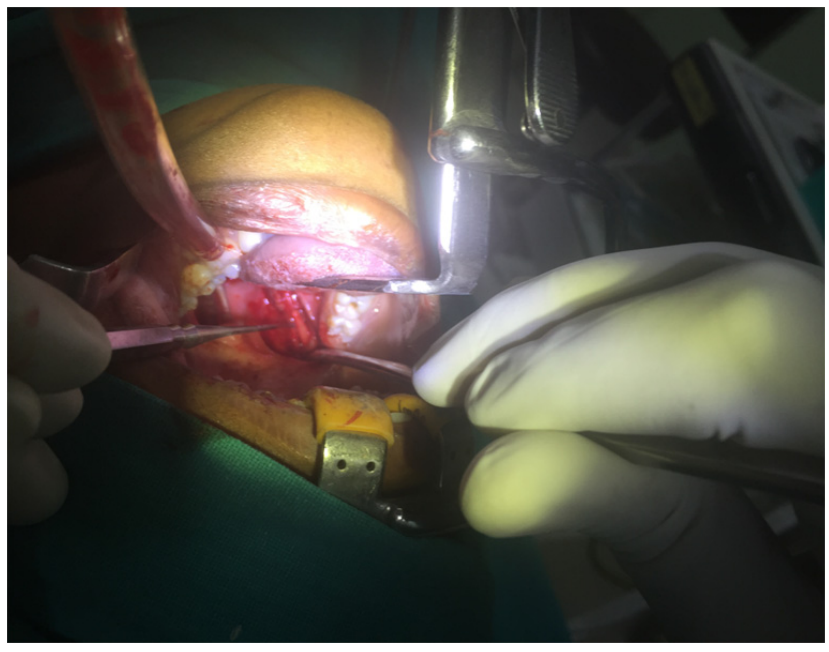

Figure 2: Exposed left styloid process

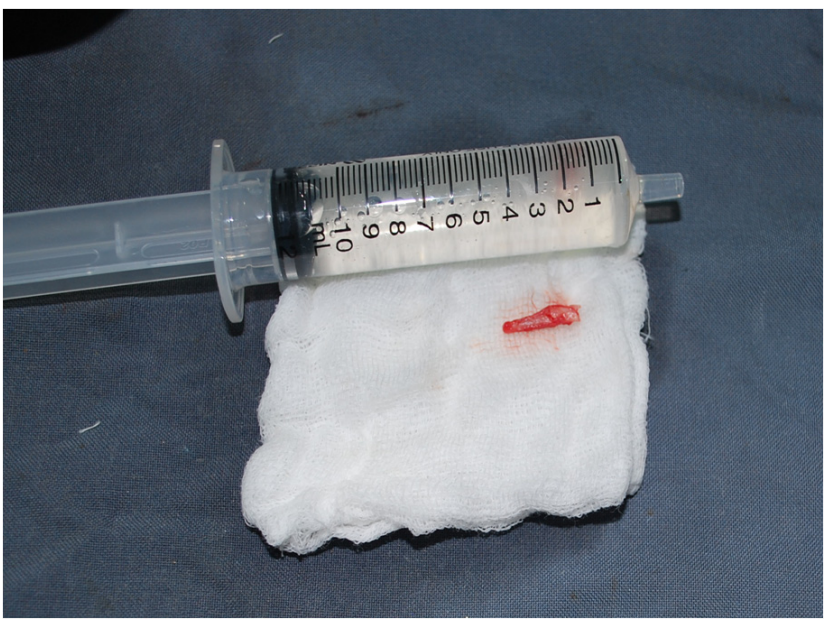

Figure 3: Resected styloid process. 
was Watt W. Eagle who first described stylalgia, later called the Eagle syndrome. ${ }^{3}$ Stylalgia also called as long styloid process syndrome or Eagle's syndrome. It is related to abnormal length of the styloid process to mineralization of the styloid ligament complex, or to calcification of digastric muscles. ${ }^{4}$

The normal length of the styloid process may vary, but with the majority of population it is 20-30 mm long, although Moffat et al (1977) measured a normal range of $15.2-47.7 \mathrm{~mm}$ and for Gossman et al (1977) a considerable variation occurs at e.g., 50$75 \mathrm{~mm} .{ }^{5,6}$ If styloid process is $30 \mathrm{~mm}$ or longer then Eagle syndrome is considered. In this patient, both thestyloid process are elongated with $5.2 \mathrm{~cm}$ on right side and $5.7 \mathrm{~cm}$ on left which was the cause of pain on left side. The syndrome is most commonly seen clinically after $3^{\text {rd }}$ decade of life because regional ligaments and the soft tissues of the styloid process become less elastic with age and offer more resistance to surrounding hard tissue structures. Patient in this case report was in the second decade of life. However, few cases in children are also reported. It can be the consequence of a difficult endotracheal intubation leading to a mineralisation of the styloid process and calcification of the ligament complex. ${ }^{6}$ There is no significant sex predilection in occurrence of mineralization of the styloid process; however, symptoms are more common in females. This case supports female preponderance. The epidemiological incidence has been reported to be between 1.4-30\%. Approximately $4 \%$ of the population has el ongated styloid process, but only 4 to $10.3 \%$ of this group has its symptoms. ${ }^{7}$

Symptoms of this syndrome include: pharyngeal pain localized in the tonsillar fossa, radiating to the oesophagus, to the hyoid bone, painful head rotation and lingual movements. The pain is exacerbated by swallowing and chewing, foreign body sensation (globus hystericus) and voice change lasting for only a few minutes. ${ }^{8} \mathrm{~A}$ variety of additional symptoms have been reported such as clicking jaw, unilateral pain and it radiates to the neck, tongue, chest or TMJ and facial paraesthesia, hypersalivation, sometimes visual problems, dysphagia and pharyngeal spasm. ${ }^{9}$ Some studies have shown a close correlation between long styloid syndrome and previous tonsillectomy, rheumatoid diseases and endocrinological disorders. ${ }^{10}$

The pathophysiological mechanisms for the pain of ES include: (1) Compression of the neural elements, the gl ossopharyngeal nerve, lower branch of the trigeminal nerve, and/ or the chorda tympani by the el ongated styloid process. (2) Stretching and fibrosis involving the fifth, seventh, ninth, and tenth cranial nerves in the post-tonsillectomy period. (3)Degenerative and inflammatory changes in the tendonous portion of the stylohyoid insertion, a condition called insertion tendinosis. (4) Impingement on the carotid vessels by the styloid process, producing irritation of the sympathetic nerves in the arterial sheath. (5) Irritation of the pharyngeal mucosa by direct compression by the styloid process. ${ }^{11}$ The diagnosis of ES must be based on a good medical history and physical examination. Careful intraoral palpation by placing the index finger in the tonsillar fossa and applying gentle pressure referred pain is reproduced which is diagnostic of Eagle's syndrome. A styloid process of normal length is usually not palpable. In addition, OPG or a cranial radiograph using a lateral projection, and computed tomography (3D CT) are necessary to confirm the diagnosis. 3D CT scan in this case confirmed the bilateral elongation of the styloid processes and diagnosis of ES of left side, eventhough styloid process on right side elongated but patient was asymptomatic.

Langlais et al (1986) classified el ongated styloid process and mineralised styloid complexes based on the radiographic appearance and structures as follows: Type I: the elongated type pattern represents an uninterrupted process. Type II: characterized by a single pseudoarticulation that seems an articulated el ongated styloid process Type III: represents an interrupted process that gives the appearance of multiple pseudo-articulations within the ligament. The type III pattern of classification can be nodular or completely calcified. CT scan in this case shows type-ll elongated styloid process (Figure 1B). ${ }^{10}$ Differential diagnosis include neuralgia of sphenopalatine ganglia, temporomandibular arthritis, glossopharyngeal and 
trigeminal neuralgia, chronic tonsillo-pharyngitis, cervical vertebral arthritis, benign or malign neoplasms, and migraine type headache.

Treatment can be conservative or surgical. Conservative treatment options have included transpharyngeal injection of steroids and lignocaine, nonsteroidal anti-inflammatory drugs, and transpharyngeal manipulation with manual fracturing of the styloid process. The most satisfactory and effective treatment is surgical shortening of the styloid process through either an intraoral or external approach. In this case report, surgical shortening of left styloid process was done by removing $2 \mathrm{~cm}$ of the process by intra-oral approach, after removing the tonsil (Figure 2 and 3). Transoral resection causes no outside scars, but involves the risk of deep cervical infection and possible neurovascular injury. ${ }^{11}$ The reported case was successfully treated using transoral resection with no untoward surgical complications.

\section{CONCLUSION}

In patients presenting with symptoms in the throat with associated headaches or facial pain, a thorough detailed case history and physical examination of the head and neck are mandatory. The diagnosis of Eagle's syndrome is made with a history and finding of an elongated styloid process in the tonsillar fossa, of which palpation reproduces the symptomatology. Traditionally, treatment has been one of surgical excision of the styloid process. An awareness of pain syndromes related to the styloid process is important to all health practitioners involved in the diagnosis and treatment of neck and head pain.

\section{REFERENCES}

1. Savranlar A, Uzun L, U gur MB, Ozer T. Three-dimensional CT of Eagle's syndrome. Diagn Interv Radiol 2005; 11:2069.

2. Politi M, Toro C, Tenani G. A rare cause for cervical pain: Eagle's syndrome. Int J Dent 2009.

3. Fini G, Gasparini G, Filippini F, Becelli R, Marcotullio M. The long styloid process syndrome or Eagle's syndrome. J ournal of Cranio-Maxillofacial Surgery 2000; 28:123-7.

4. Mortellaro C, Biancuccci P, Picciolo G, Vercellino V. Eagle's syndrome. I mportance of a corrected diagnosis and adequate surgical treatment. J Craniofac Surg 2002; 13: 755-8.

5. Moffat DA, Ramsden RT, Shaw HJ. The styloid process syndrome: Aetiological factors and surgical management. J Laryngology Otology 1977; 91:279-94.

6. Gossman J R J r, Tarsitano J J. The styloid-stylohyoid syndrome. J ournal of Oral Surgery 1977; 35:555-60.

7. Murtagh RD, Caracciolo J T, Fernandez G. CT findings associated with Eagle syndrome. AJ NR Am J Neuroradiol 2001; 22:1401-2.

8. Quereshy FA, Gold ES, Arnold J, Powers MP. Eagle's syndrome in an 11-year-old patient. J Oral Maxillofac Surg 2001; 59:94-7.

9. Godden DRP, Adam S, Woodwards RTM. Eagle's syndrome: An unusual cause of a clicking jaw. Brit Dent J 1999; 186:489-90.

10. Langlais RP, Miles DA, Van Dis ML. Elongated and mineralized stylohyoid ligament complex: A proposed classification and report of a case of Eagle's syndrome. Oral Surgery Oral Med Oral Path 1986; 61:527-32.

11. Ceylan A, Koybasiog lu A, Celenk F, Yilmaz O, Uslu S. Surgical treatment of elongated styloid process: experience of 61 cases. Skull Base 2008; 18(5):289-95.

\section{Gain quick access to our journal online View our journal at www.nacd.in}

